\title{
Predictors of Infection and Mortality in Living Donor Liver Transplantation
}

\author{
WESAM S. MORAD, M.D.*; AMR M. AZIZ, M.D.** and AMAL EL-SHARNOBY, M.D.*** \\ The Departments of Epidemiology \& Preventive Medicine*, Hepatopancreato-Biliary Surgery** and Clinical Pathology***, \\ National Liver Institute, Menoufiya University, Menoufiya, Egypt
}

\begin{abstract}
Background: Infection is the most frequent cause of morbidity and mortality following liver transplantation in Egypt.

Aim of the Study: This study was directed at assessing the frequency of infection occurring in the early postoperative period and the possible associated preoperative, operative, and postoperative predictors of infection and mortality in patients underwent living related liver transplantation at National Liver Institute.

Patients and Methods: This was prospective cohort hospital based study described rate of infections occurring in the early postoperative period and their predictors as well as predictors of mortality. It was carried out on 40 living donor liver transplantation patients' who provided informed consent to participate. Participants were interviewed to gather predictor factors data using multiple question model previously prepared questionnaire, biophysiologic measures and observation checklist.
\end{abstract}

Results: Living donor liver transplantation complicated Infection was $68.8 \%$ in which $59.1 \%$ of infection episodes occurred in the first month post transplantation and the incidence declined thereafter. High infection rate was associated with prolonged operative time $(14.8 \pm 3.07)$. Infection induced mortality was $77.8 \%$.

Conclusion: Most of infection episodes induced mortality occurred in the first month post liver transplantation due to bad selection of donors which were associated with risk factors of infection and predictors of mortality.

Recommendations: Careful evaluation of donor and recipient prior to liver transplantation prevents serious post transplantation infection, either by excluding risky donors or by defining the need for specific antimicrobial therapy post liver transplantation.

Key Words: Nosocomial Infection - Living donor liver Transplantation - Prevention strategies - biophysiologic measures - Septic techniques.

Correspondence to: Dr. Wesam S. Morad, E-Mail: wesammorad@yahoo.com

\section{Introduction}

LIVER transplantation (LT) is widely accepted as an effective therapeutic modality for a variety of irreversible acute and chronic liver disease. The success of liver transplantation has increased steadily over the last two decades and survival advances have been made since the first human liver transplant. This procedure has become routine with an excellent outcome in terms of both quality and length of survival [1].

Despite significant improvements in the medical management of the complications of liver cirrhosis including hepatocellular carcinoma, liver transplantation (LTx) remains the only definitive treatment option for patients with end-stage liver disease. Significantly improved graft and patient survival rates have been observed over time and, in the last 15 years, are relatively stable, with an overall survival rate of $85 \%$ in the first year and $75 \%$ at $5 \mathrm{yr}[2]$.

With few exceptions, all patients who undergo transplantation are committed to lifelong immunosuppressant therapy to prevent graft rejection. Inadequate immunosuppression can result in graft loss, whereas injudicious use of immunosuppression can result in life threatening infection or development of PTLD [3].

Infections remain a major complication of all types of transplantation. It can contribute to the patient's death. Bacteria can cause serious infection after solid-organ transplantation (SOT), with significant morbidity and mortality rates $[\mathbf{4 , 5 , 6}$.

Despite recent advances, infectious complications remain a significant contributor to morbidity and mortality after liver transplantation, affecting both patient and graft survival. Following transplantation, one third to one half of liver transplant recipients experience an infectious complication 
with over $80 \%$ of infections occurring within the first 6 months following transplant. Infectious complications are the cause of death in over 15$25 \%$ of all liver transplant recipients but are responsible for over half of deaths in the first year following transplant. Infection remains the most common cause of death for the first 3 years after liver transplant. Bacterial infections predominate and include presentations such as bloodstream, abdominal, wound, or biliary tract infection. Liver transplant patients are also particularly susceptible to fungal infections, predominantly candidemia, invasive aspergillosis, and cryptococcal infection. [7]

Infectious complications are major causes of morbidity and mortality after liver transplantation, despite advances in surgical technique, posttransplant care, hospital environments, immunosuppression, infectious disease treatment, infection prevention and prophylaxis in liver transplant (LT) recipients. LT recipients are more likely to develop bacterial infections than other transplant recipients because of the complexity of the surgical procedure, which includes penetration of the hepatobiliary system [8]

The aim of this study is to assess frequency of infection occurring in the early postoperative period and the possible associated preoperative, operative, and postoperative predictors of infection and mortality in patients underwent living donor liver transplantation (LDLT) during Intensive care unit stay at National Liver Institute Hospital.

\section{Material and Methods}

\section{Ethics statement:}

The study protocol was approved by the ethical Committee at National Liver Institute Medical Ethical Committee prior to patient identification and data collection. A written consent was taken from all study population and who refused to participate was excluded from the study.

\section{Study population:}

40 consecutive liver transplant recipients' of LDLT from 1 st December 2016 till 1 st December 2017 were interviewed and their medical records were reviewed.

\section{Study design and data collection:}

We performed prospective cohort hospital based study to investigate the risk factors and predictors of infection and overall hospital mortality and infection-related 30-day mortality in LDLT recipients. Each LDLT recipient was observed weekly from the first post-LDLT day until the end of the second month postoperatively or till his/her death. Demographic and clinical characteristics included age, sex, body temperature at the onset of infection, site and date of diagnosis of infection, nosocomial origin of infection, empirical antimicrobial therapy, intensive care unit (ICU) stay, and septic shock, and the laboratory records of these recipients were analyzed. The laboratory variables were collected within the first 24 hours after the microbiological culture was drawn, including serum creatinine and albumin levels and white blood cell, platelet, lymphocyte counts, and C-reactive protein (CRP). All episodes of infection were reviewed, and only the first episode was included for further statistical analyses.

The presence of infection, including bacteremia, pneumonia, peritonitis, pleuritis, vascular catheter and urinary tract infection was defined based on the criteria suggested by the US Centers for Disease Control and Prevention [9].

Appropriate antimicrobial therapy was defined as use of a drug to which the isolated pathogen was susceptible in vitro within 48 hours of sampling for culture [10]

Infection was considered to be nosocomially acquired in patients who had been hospitalized for 48 hours or longer. Infection was categorized as early onset if it occurred 2 months (60 days) or less after SOT, or late onset if it occurred [ $\mathbf{\Omega}$

Septic shock was diagnosed in recipients who had a positive culture and developed persistent dysfunction of at least one organ caused by hypoperfusion that was unresponsive to intravenous fluid challenge and unexplained by other causes [11]

Mortality was regarded as related to infection when death was associated with clinical signs of active infection without evidence of any other cause [12]

\section{Antibiotic prophylaxis protocol:}

Patients were treated with cefotaxime and metronidazole each for the first 10 days after surgery. Oral mycostatin every 6 hours was given for Candida prophylaxis 4 days pre-operative and until discharge. All patients received kanamycine (syrup for pediatric in a dose of $50 \mathrm{mg} / \mathrm{kg} /$ day on 4 divided doses and kanamycine $250 \mathrm{mg}$ capsule/ 6 hours for adults) and lactulose syrup $60 \mathrm{ml}$ oral/day divided on 4 doses 4 days preoperative for bowel decontamination. In cases of established fungal infection Fluconazole in the therapeutic dose $(10 \mathrm{mg} / \mathrm{kg} / \mathrm{day}$ IV) was given. 


\section{Immunosuppressant protocol:}

Standard immunosuppressants included FK506 and corticosteroids. FK506 was administered orally and its dose was adjusted to obtain blood level of 10 to $15 \mathrm{ng} / \mathrm{ml}$ for at least the first 2-3 weeks. Intravenous methyl prednisolone in a dose of $10 \mathrm{mg} / \mathrm{kg}$ administered intra-operatively. This was reduced to $1 \mathrm{mg} / \mathrm{kg} / \mathrm{dose}$ once daily for 3 days after surgery and rapidly tapered so that on day 7 the patient was receiving $0.3 \mathrm{mg} / \mathrm{kg} /$ day of methyl prednisolone. Oral therapy of equivalent dose of prednisone was employed when the patient was able to take oral medicine. The dose was reduced to $0.1 \mathrm{mg} / \mathrm{kg} / \mathrm{day}$ after 3 months after transplantation. Acute rejection episodes were treated by either increasing the dose of FK506 or intravenous pulse therapy of methyl prednisolone. Cyclosporine (in a dose of $8-10 \mathrm{mg} / \mathrm{kg} / \mathrm{day}$ ) and MMF (in a starting dose of $1 \mathrm{~g}$ /day on two divided doses) were also administered to some patients, generally when the dose of FK506 had to be decreased or discontinued because of its side effects.

\section{Post-transplantationmanagement:}

Surveillance cultures from throat, nose, blood, urine, stool and any other body fluid (e.g. biliary tube output, drains...etc) were obtained every week for the first 2 to 3 months after transplant for most of patients. Other cultures were ordered as dictated by the clinical situation. All intravascular catheters tips were submitted to culture after removal.

\section{Tools of the study:}

To achieve the aim of the study and to collect the necessary data, the researcher designed three tools based on extensive review of the relevant literature. All tools were tested for content validity by experts in the field of the study to ascertain their relevance and completeness, and then all modifications were done accordingly.

\section{Tools I: Interview questionnaire sheet:}

Included patients demographic data; age, sex, educational level and occupation; indication of transplantation and present medical history; it included data such as preoperative medical disorders, preoperative infections, preoperative ascites, and preoperative attacks of encephalopathy etc). The transplanted patients were grouped into three categories, Cholestatic group, Hepatocellular group and other underlying causes.

\section{Tools II: Biophysiologic measures:}

This part was included the preoperative and postoperative laboratory investigations which act as a sepsis indicators to help in diagnosing the infection, such as (Total Leukocyte Count, Creactive protein, Swabs and Cultures).

Tools III: Observation checklist included four parts:

- Part one:Preoperative preparation of the patients

- Part two: Operative details

- Part three:The operating room environment which was used to assess the following (ventilation system, cleaning and disinfection of environmental surfaces, microbiologic samples, sterilization of surgical instruments and surgical attire and drapes).

- Part four: Post transplantation management which was used to assess postoperative surgical incision care, care of IV line and assess for blood glucose control.

\section{Pilot study:}

It was initially carried out prior to data collection on 10 patients undergone LDLT at from 1 st September 2016 till 1 st December 2016 in which clarity, feasibility and applicability of the developed tools were evaluated. The pilot study sample was excluded from the applied research sample.

\section{Follow-up:}

The follow-up time of all recipients was at least 1 month after the onset of infection. It was done through determining the mean time of ICU stay and NLI hospital stay.

\section{Outcome:}

It was detected through studying incidence of mortalities and infection-type related mortalities.

\section{Statistical analysis:}

Continuous variables were expressed as means \pm standard deviation. The $\chi^{2}$ and Fisher exact tests were used to analyze categorical variables. Univariate analysis was applied to examine the association between demographic/clinical variables and incidence of occurrence of infection. We included variables identified $(p, 0.10)$ by univariate analyses. Odds ratios (ORs) with 95\% confidence interval (CIs) were calculated. Cumulative differences in the incidence of infection in LDLT were analyzed by use of the Kolmogorov Smirnov test (Epistat). Statistical analyses were performed using SPSS for Windows, version 23.0 (IBM Corporation, Armonk, NY, USA). Statistical significance was defined as $p, 0.05$ (two-tailed).

\section{Results}

During the 12-month study period, 40 LDLT recipients were enrolled. $85 \%$ were adult males 
and $15 \%$ were females. The mean age \pm SD was $40.4 \pm 14.2$ years (range, 18 years to 52years). 28 patients $(70 \%)$ out of 40 patients had at least one episode of infection. Twenty patients aged $\geq 30$ years $(71.4 \%)$, while 8 patients aged $<30$ years (28.6\%) Fig. (1). $78.6 \%$ of infected cases were male (22 cases), while $21.4 \%$ of infected cases were female (6 cases) (Table 1$)$.

The researcher studied the association between practicing aseptic technique and incidence of infection in LRLT showed that patients' with negative maintain sterilization of all invasive equipments, negative care for cannula and CVP daily, negative maintaining aseptic technique during inserting cannula and catheter, cannula and catheter removal as early as possible, and contact of unsterilized equipments in ICU were 135 times, 33 times, 23 times, 8 times and 18 times risky respectively to acquire postoperative infection than others (Table 2). Also, studying the Association between bad practice of chest exercise and incidence of postoperative infection showed that patients' with bad practice of chest exercise through irregular physiotherapy for breathing and coughing and irregular chest exercise are 66 times and 12 times risky to acquire postoperative infection than others (Table 2).

The researcher studied the association between length of ICU stay, LX LT operation mean time and both preoperative TLC and CRP mean value and incidence of postoperative infection in LR LT Pts, showed that patients' with more than 8 days admission in ICU, more than 14 hours operative time, more than 8.2 mean value of CRP and more than 9.8 mean value of TLC are 135 times, 91.1 times, 40.3 times and 7 times risky respectively to acquire postoperative infection than others (Table 2).

In univariate analysis, the following variables were significantly associated with infection-related 30-day mortality: Temperature $\geq 39^{\circ} \mathrm{C}(p=0.026)$, late-onset of infection ( $p=0.022)$, ICU stay ( $p=$ $0.003)$, septic shock ( $p=0.001)$, creatinine level $\geq 1.5 \mathrm{mg} / \mathrm{dL}(p=0.041)$, and platelet count $\leq 50,000 /$ $\mathrm{mm}^{3}(p=0.002)$. In multivariate analysis, platelet count $\leq 50,000 / \mathrm{mm}^{3}$ (OR 12.8, 95\% CI $1.3-126.8$; $p=0.030)$ and septic shock at of infection (OR $89.98,95 \%$ CI 13.2-122.8; $p=0.004$ ) were significantly related to a higher risk of 30-day mortality associated with infection (Table 3 ).

$78.6 \%$ male sex was the most common among infected LDLT patients Fig. (1).
The number of episodes of infections and causative organisms and time of onset showed in Fig. (2).

The overall survival showed that median survival in infected cases were 22 months while median survivals in non infected cases were 27 months. There is no statistical significant difference between both groups ( $p$-value >0.05). Fig. (3).

Table (1): Demographic, laboratory, and clinical variables of 40 LDLT recipients'.

\begin{tabular}{|c|c|}
\hline Characteristics & Value \\
\hline Age, mean years $\pm \mathrm{SD}$ & $40.4 \pm 14.2$ \\
\hline Male sex, n (\%) & $34(78.6)$ \\
\hline Female sex, n (\%) & $6(21.4)$ \\
\hline Temperature $39^{\circ} \mathrm{C}$ or greater, $\mathrm{n}(\%)$ & $8(20.0)$ \\
\hline Nosocomial origin, n (\%) & $36(90.0)$ \\
\hline Inappropriate antimicrobial use, n (\%) & $23(57.5)$ \\
\hline ICU stay, n (\%) & $40(100.0)$ \\
\hline Septic shock, n (\%) & $3(7.5)$ \\
\hline \multicolumn{2}{|l|}{ Site of infection, $n(\%)$ : } \\
\hline Bloodstream & $7(31.8)$ \\
\hline Lung & $6(27.3)$ \\
\hline Intra-abdomen/biliary tract & $3(13.6)$ \\
\hline Urinary tract & $4(18.2)$ \\
\hline Vascular catheter & $2(9.1)$ \\
\hline Multiple culture-positive sites & $5(22.7)$ \\
\hline \multicolumn{2}{|l|}{ Time of infection onset, $n(\%)$ : } \\
\hline$<2$ months post transplant (early onset) & $13(59.1)$ \\
\hline$\geq 2$ months post transplant (late onset) & $9(40.9)$ \\
\hline \multicolumn{2}{|l|}{ Laboratory variablesfrom blood, $n(\%)$ : } \\
\hline Platelet count, $50,000 / \mathrm{mm}^{3}$ & $14(35.0)$ \\
\hline Lymphocyte count, $300 / \mathrm{mm}^{3}$ & $13(32.5)$ \\
\hline Albumin, $30 \mathrm{~g} / \mathrm{L}$ & $7(17.5)$ \\
\hline WBC count. $15,000 / \mathrm{mm}^{3}$ & $12(30.0)$ \\
\hline Creatinine. $1.5 \mathrm{mg} / \mathrm{dL}$ & $23(57.5)$ \\
\hline Related mortality, n (\%) & $8(28.6)$ \\
\hline Overall in-hospital mortality, n (\%) & $11(27.5)$ \\
\hline \multicolumn{2}{|l|}{ Survival, mean months $\pm S D:$} \\
\hline $\begin{array}{l}\text { Survival duration of infected cases } \\
\text { range (3-48 months) }\end{array}$ & $20.25 \pm 11.03$ \\
\hline $\begin{array}{l}\text { Survival duration of non infected } \\
\text { cases ( } 8-39 \text { months) }\end{array}$ & $25.25 \pm 11.14$ \\
\hline $\begin{array}{l}\text { Abbreviations: } \\
\text { LDLT : Living donor liver transplantation. } \\
\text { SD : Standard deviation. } \\
\text { ICU : Intensive care unit. } \\
\text { WBC : White blood cell. }\end{array}$ & \\
\hline
\end{tabular}


Table (2): Predictors of infection in LDLT recipients'.

\begin{tabular}{|c|c|c|c|}
\hline Studied variables & $\begin{array}{l}\text { Positive } \\
\text { infection }\end{array}$ & $p$-value & OR $95 \%(\mathrm{CI})$ \\
\hline Total, n (\%) & $28(70.0)$ & & \\
\hline \multicolumn{4}{|l|}{ Univariate analysis, $\mathrm{n}(\%)$ : } \\
\hline \multicolumn{4}{|l|}{ Preoperative predictors: } \\
\hline CRP mean value $>8.2$ & $22(78.6)$ & $<0.001$ & $40.3(3.81024 .8)$ \\
\hline TLC mean value $>9.8$ & $20(71.4)$ & 0.024 & $7.5(1.32-48.02)$ \\
\hline \multicolumn{4}{|l|}{ Operative predictors: } \\
\hline Operative time mean time $>14$ hours & $25(89.3)$ & $<0.001$ & $91.1(7.1-2816.5)$ \\
\hline \multicolumn{4}{|l|}{ Postoperative predictors: } \\
\hline No care for cannula and CVP daily & $21(75.0)$ & $<0.001$ & $33(3.2-819.3)$ \\
\hline No maintenance of aseptic technique during inserting cannula and catheter & $23(82.1)$ & 0.004 & $23(3.1-223.1)$ \\
\hline No cannula and catheter removal as early as possible & $17(60.7)$ & 0.028 & $7.73(1.2-63.35)$ \\
\hline No hand hygiene (hand washing and alcohol hand rub) & $20(71.4)$ & 0.002 & $27.5(2.7-671.7)$ \\
\hline No wearing of gloves & $21(75.0)$ & 0.007 & $15(2.2-132.1)$ \\
\hline Not keeping sterilization of all invasive equipments in ICU & $27(96.4)$ & $<0.001$ & $135(8.7-5303.8)$ \\
\hline No aseptic technique and Avoid contact with unsterilized equipments in ICU & $24(85.7)$ & 0.0074 & $18(2.68-148.3)$ \\
\hline No maintenance of physiotherapy for breathing or coughing regularly & $24(85.7)$ & $<0.001$ & $66(5.6-1833.8)$ \\
\hline No maintenance of chest exercise regularly: & $20(71.4)$ & 0.005 & $12.5(1.9-107.1)$ \\
\hline ICU stay mean time $>8$ days & $27(96.4)$ & $<0.001$ & $135(8.7-5303.8)$ \\
\hline \multicolumn{4}{|l|}{ Multivariate analysis, $\mathrm{n}(\%)$ : } \\
\hline \multicolumn{4}{|l|}{ Operative: } \\
\hline Operative time mean time $>14$ hours & \multicolumn{2}{|c|}{$<0.001$} & $66(8.6-71.2)$ \\
\hline \multicolumn{4}{|l|}{ Postoperative predictors: } \\
\hline Not keeping sterilization of all invasive equipments' in ICU & \multicolumn{2}{|c|}{$<0.001$} & $72(10.7-93.4)$ \\
\hline ICU stay mean time $>8$ days & \multicolumn{2}{|c|}{$<0.001$} & $70(9.2-83.8)$ \\
\hline No care for canula and CVP daily & \multicolumn{2}{|c|}{0.004} & $33(4.2-39.3)$ \\
\hline
\end{tabular}

Abbreviations: LDLT: Living Donor Liver Transplantation. OR: Odds Ratio. CI: Confidence Interval. CVP: Central Venous Catheter. ICU: Intensive Care Unit. CRP: C- Reactive Protein. TLC: Total Leucocytic Count.

Table (3): Predictors for infection-related mortality in LDLT recipients'.

\begin{tabular}{lllll}
\hline Characteristics & Related mortality & Survival & $p$-value & OR 95\% (CI) \\
\hline Total, n (\%) & $8(28.6)$ & $20(71.4)$ & & \\
Univariate analysis, $n(\%)$ : & & & & \\
Age $\geq 40$ years & $5(62.5)$ & $14(70.0)$ & 0.994 & $0.99(0.36-2.77)$ \\
Male gender & $6(75.0)$ & $15(75.0)$ & 0.363 & $0.61(0.21-1.78)$ \\
Temperature $\geq 39^{\circ} \mathrm{C}$ & $3(37.5)$ & $3(15.0)$ & 0.026 & $3.67(1.17-11.5)$ \\
Inappropriate antibiotics & $4(50.0)$ & $12(60.0)$ & 0.394 & $0.66(0.25-1.72)$ \\
Nosocomial infection & $8(100.0)$ & $18(90.0)$ & 0.165 & $4.67(0.5-41.03)$ \\
Liver transplant & $3(37.5)$ & $6(30.0)$ & 0.755 & $1.17(0.43-3.21)$ \\
Multiple culture-positive sites & $2(25.0)$ & $3(15.0)$ & 0.160 & $2.25(0.73-6.97)$ \\
Late-onset infection & $5(62.5)$ & $6(30.0)$ & 0.022 & $3.16(1.18-8.48)$ \\
ICU stay & $8(100.0)$ & $11(55.0)$ & 0.003 & $23.13(2.9-186.1)$ \\
Septic shock & $4(50.0)$ & $1(5.0)$ & 0.001 & $12.13(3.1-48.3)$ \\
Platelet count, 50,000/mm ${ }^{3}$ & $4(50.0)$ & $4(20.0)$ & 0.002 & $5.23(1.8-15.14)$ \\
Lymphocyte count, 300/mm & $3(37.5)$ & $5(25.0)$ & 0.066 & $2.60(0.94-7.21)$ \\
Albumin, 30g/L & $2(25.0)$ & $2(10.0)$ & 0.055 & $3.62(0.97-13.5)$ \\
WBCs count. 15,000/mmv & $3(37.5)$ & $6(30.0)$ & 0.994 & $1.00(0.36-2.79)$ \\
Creatinine. $1.5 \mathrm{mg} / \mathrm{dL}$ & $6(75.0)$ & $9(45.0)$ & 0.041 & $2.89(1.05-7.97)$ \\
Multivariate analysis, $n(\%):$ & & & & $89.98(13.2-122.8)$ \\
Septic shock & & & 0.004 & $12.8(1.3-126.8)$ \\
Platelet count $<50,000 / \mathrm{mm}^{3}$ & & & 0.030 & \\
\hline
\end{tabular}

Abbreviations: LDLT: Living Donor Liver Transplantation. OR: Odds Ratio. CI: Confidence Interval. ICU: Intensive Care Unit. WBCs: White Blood Cells. 


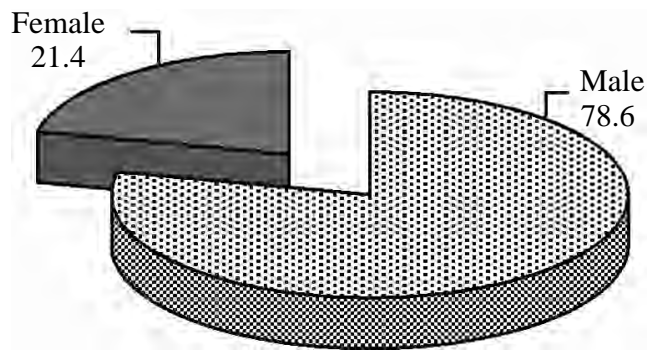

Fig. (1): Gender distribution among infected LDLT recipients'.

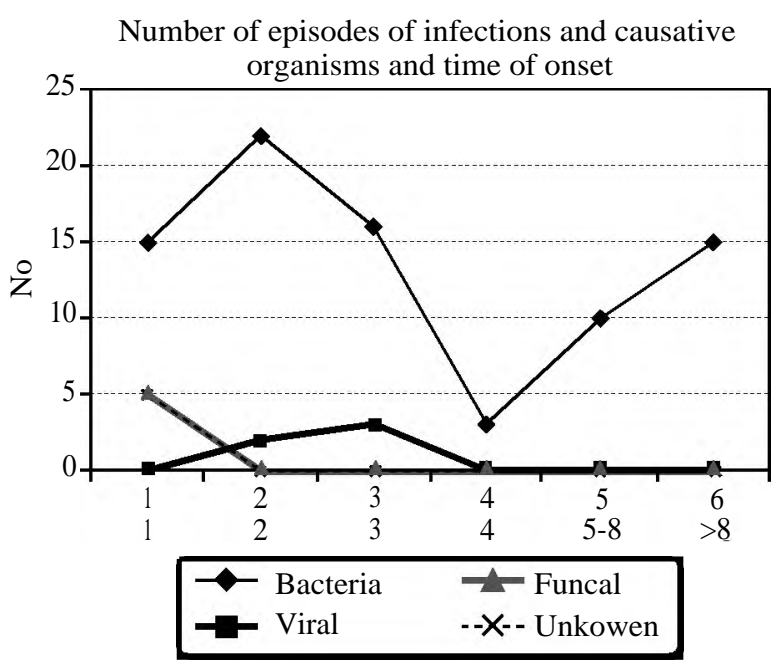

Fig. (2): The number of episodes of infections and causative organisms and time of onset in LDLT recipients'.

Log Rank test $=0.12 \quad p$-value $>0.05$

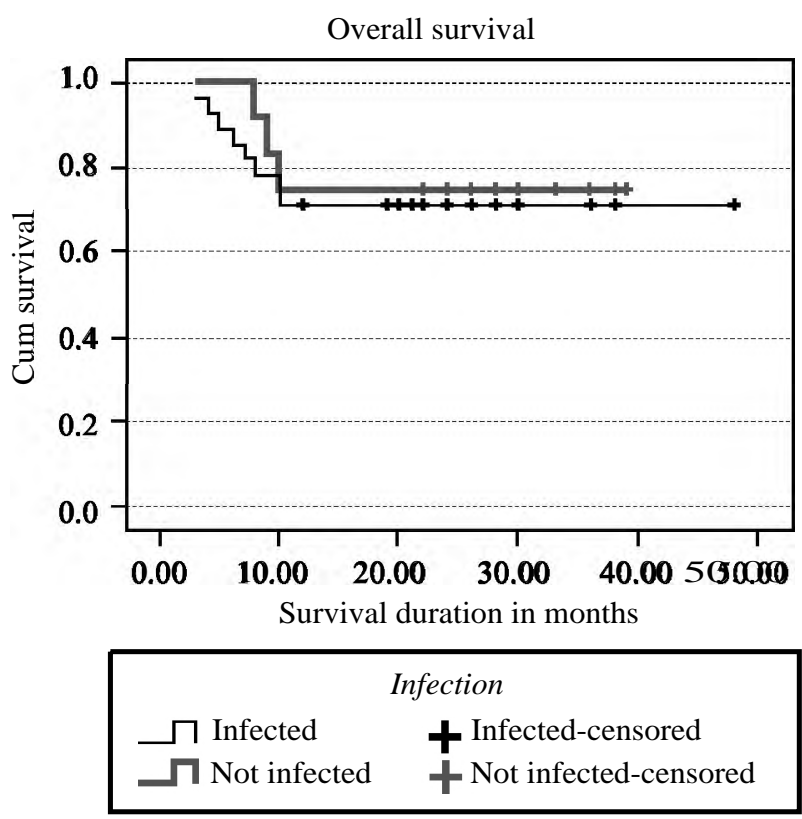

Fig. (3): Kaplan Meier curve of overall survival of LDLT recipients'.

Kaplan-Meier survival curve of overall survival, Shows that median survival in in infected cases was 22 months while median survival in non infected cases are 27 months. There is no statistical significant difference between both groups $(p$-value $>0.05)$.

\section{Discussion}

Invasive bacterial infections have become a leading contributor to patient morbidity and mortality among LDLT recipients [13]. Despite measures such as the use of protective barriers, antimicrobial prophylaxis, and vaccination, infections still represent a major cause of morbidity and mortality after liver transplantation [14]

Despite the major advances in immunosuppressant regimens, perioperative management and medical care have contributed to improvements in the survival rate of solid organ transplant recipient. Infection continues to be a leading cause of postoperative mortality and morbidity so the degree of postoperative infection is influenced by various factors, such as poor preoperative condition, immunosuppressive therapy, prophylactic use of antibiotics (antimicrobial agents), regional bacterial epidemiology and invasive ducts. Furthermore, the hospital environment and management in different clinical divisions also affect the infection status $[15,16,17]$.

In this study 28 patients (70\%) out of 40 patients had at least one episode of infection with $8(28.6 \%)$ patient died due to infection. Liver transplantation had one of the highest rates of postoperative infection among all solid organ transplant procedures [18]. It had been reported that the postoperative bacterial infection rate might be up to more than $60 \%$ and accounted for an in-hospital mortality rate of $30 \%-50 \%$ [19]

In this study hand hygiene (hand washing and alcohol hand rub) were 27.5 risky to acquire postoperative infection than others. For the last 160 years, the scientific knowledge of how to reduce hand contamination and thereby decrease patient infections from the seminal work on hand washing by the Hungarian obstetrician, Ignaz Semmelweis [20]. Hand washing has been indicated to be the single most important step in breaking the chain of infection. The World Health Organization, 2009 indicates that hands should be decontaminated before clean and aseptic procedures, and hand washing is a key recommendation in national care bundles that aim to reduce the risk of healthcareacquired infections associated with PVCs [21,22]

The incidence rate of infection in LDLT recipients was $70 \%$ ( 28 of 40 ), in the present study. Although in more transplant centers, including ours, higher-immunosuppression regimens are used in liver-transplant recipients, the incidence rate of infection in liver because patients undergoing liver had several conditions that favor postoperative 
infection, such as preoperative malnutrition due to end-stage liver disease, insulin resistance, major surgical trauma, massive intraoperative bleeding and transfusions, the placement of various catheters, and long duration of antibiotic use before and after transplantation, which could enhance the likelihood of emergence of infection and resistant strains of microorganisms.

Seventy percent of recipients had infection with nosocomial origin in our present study, in alignment with previous studies $[\mathbf{2 3 , 2 4 ]}$ reporting that during certain period, major transplant centers in the United States reported a bacterial infection incidence range of $53 \%-56 \%$. In a report of a Swiss cohort in the 2000 s, $47 \%$ of the patients contracted bacterial infections.

Kim et al. [2] reported rate of $30.2 \%$ during the first month and $67.9 \%$ during the total follow-up period (mean, $672 \mathrm{~d}$ ). Others reported rates of $14.1 \%$ in the first $3-\mathrm{mo}$, and $75 \%$ and $42.9 \%$ in deceased and living-donor LT recipients, respectively [25]

The possible reasons to explain this included MDR being defined as resistance to three or more major classes of antibiotics historically effective against infection (fluoroquinolones, carbapenems, aminoglycosides, penicillins, and cephalosporins) in the study conducted by Kusne et al., whereas in our present study, MDR was defined as acquired non susceptibility to at least one agent in three or more antimicrobial categories, which included nine classes of antibiotics.

In this study negative Care for cannula and CVP daily, Maintain aseptic technique during inserting or removing cannula and catheter as early as possible were $33,23,8$ times risky respectively to acquire postoperative infection than others.

Observation and monitoring of the peripheral venous catheter (PVC) site and localized tissue are essential to ensure any significant changes are identified and responded to appropriately, to reduce the risk of complications.

Webster et al., [26] stated that the clinical necessity for PVC should be under constant review. Clinical requirement should be considered at least daily and the portal venous catheter (PVC) should be removed as soon as it is deemed unnecessary. It has been suggested that clinical indication alone should drive the removal of PVCs. However, national guidelines state that removal should be considered if the PVC has been in situ for longer than 72 hours [22] or 72-96 hours [21], as the risk of complications increases with time [27]. PVCs inserted in emergency situations should be removed within 24 hours [28].

In this study negative contact of unsterilized equipments in intensive care unit (ICU) are 18 times risky respectively to acquire postoperative infection than others. Medical devices have become increasingly common source of health care-associated infections (HAIs) $[\mathbf{1 5 , 1 6 , 2 0 ]}$.

A growing body of literature suggests that device-associated HAIs (DA-HAIs) are among the main causes of patient morbidity and mortality within hospital intensive care units $[\mathbf{1 6 , 1 7 , 1 8}]$.

Survival after liver transplantation has improved over the years, partly due to advances in surgical techniques, and a reduction in allograft rejection. However, there remain multiple preventable conditions that contribute to the poor prognosis of liver transplant recipients. Understanding these complications may optimize management strategies, and further improve the quality of life, and survival rate of patients.

The present study showed that infection was associated with high morbidity, as well as high infection-related 30-day mortality (20.0\%), in line with previous studies that reported an incidence rate of up to $6.1 \%$ and an extremely high mortality rate of up to $80 \%$ among SOT recipients with A. baumannii infection $[\mathbf{2 9 , 3 0 , 3 1 ]}$.

Septic shock associated with infection-related 30-day mortality was in agreement with a recent study claiming that the risk of A. baumannii infection-associated mortality was higher in SOT patients with septic shock [30].

The present study revealed that liver transplantation was significantly related to infection related mortality, in accordance with Moreno et al., who found liver transplantation to be a risk factor for higher mortality in transplant recipients with bloodstream infections [32].

The present study also revealed that thrombocytopenia was a risk factor associated with infection-related mortality. This finding probably reflects a confounding factor, as thrombocytopenia developed more frequently among liver recipients who presented with higher baseline clinical severity. Our study findings consolidated results from previous studies of Survived Organ Transplantation (SOT) recipients, which reported that lower platelet count to be associated with infection-related mortality $[12,33]$ 
To the best of our knowledge, this is the largest study specifically focusing on infections to investigate the epidemiology, distribution, and predictors for infection-related 30-day mortality in LDLT recipients'. However, the present study has certain limitations. Firstly, our study was a small prospective study with potential limitations, such as the relatively small number of cases and deaths, the statistical power may be insufficient. Also we may have underestimated the true frequency of infection in LDLT recipients, given that some cases received empiric courses of antimicrobial therapy before specimens for bacterial culture were obtained. Finally, though we tried to include all relevant data, other unidentified variables are probably risk factors for mortality. The strength of our study is the long study period.

\section{Conclusion:}

Maintenance of practicing aseptic technique and good sterilization were very important associated with reducing incidence of postoperative $\mathrm{Lx}$ LT infection. It was found that patients with elevated levels of preoperative CRP and TLC were risky to acquire postoperative infection. In addition prolonged operative time was considered a significant risk affecting incidence of postoperative LDLT infection. Mortality induced infection was the most common type of mortality following LDLT operations It is possibly increased with certain types of infection.

\section{References}

1- ROSALBA MORENO and MARINA BERENGUER Hepatitis C and liver transplantation. Annals of Hepatology, 1 (3): 129-135, 2006.

2- KIM W.R., STOCK P.G., SMITH J.M., HEIMBACH J.K., SKEANS M.A., EDWARDS E.B., HARPER A.M., SNYDER J.J., ISRANI A.K. and KASISKE B.L.: OPTN/SRTR 2011 Annual Data Report: Liver. Am. J. Transplant, 13: 73-102, 2013.

3- WILLIAM R. and JARNAGIN BLUMGART'S: Surgery of the Liver, Pancreas and Biliary Tract, E-Book-_Medical https://books.google.com.eg/books?isbn $=0323340873$, 2016.

4- DUMMER J.S. and SINGH N.: Infections in solid organ transplant recipients. In: Mandell GL, Bennett JE, Dolin R. Mandell, Douglas, and Bennett's Principles and Practice of Infectious Diseases. 7th ed. Philadelphia: Churchill Livingstone; 2010:3839-3850.

5- FISHMAN J.A.: Infection in solid-organ transplant recipients. N. Engl. J. Med., 357: 2601-2614, 2007.

6- SNYDER J.J., ISRANI A.K., PENG Y., ZHANG L., SIMON T.A. and KASISKE B.L.: Rates of first infection following kidney transplant in the United States. Kidney Int., 75: 3 17-326, 2009.
7- ERIKA D. LEASE: Infections and Sepsis After Liver Transplantation, Contemporary Liver Transplantation Textbook, pp 255-266, 2017

8- DUMMER J.S. and SINGH N.: Infections in solid organ transplant recipients. In: Mandell G.L., Bennett J.E., Dolin R., editors. Mandell, Douglas, and Bennett's Principles and Practice of Infectious Diseases. 7 th ed. Philadelphia, PA: Churchill Livingstone, pp. 3839-3850, 2010.

9- HORAN T.C. , ANDRUS M. and DUDECK M.A.: CDC/NHSN surveillance definition of health careassociated infection and criteria for specific types of infections in the acute care setting. Am. J. Infect. Control., 36: 309-332, 2008

10- GAO F., YE Q.F., WAN Q.Q., LIU S. and ZHOU J.: The distribution and resistance of pathogens among liver transplant recipients with Acinetobacter baumannii infections. Ther. Clin. Risk Manag., 11: 501-505, 2015.

11- KOLLEF M.H. and MICEK S.T.: Strategies to prevent antimicrobial resistance in the intensive care unit. Crit. Care. Med., 33: 1 845-1853, 2005.

12- WAN Q., YE Q. and ZHOU J.: Mortality predictors of bloodstream infections in solid-organ transplant recipients. Exp. Clin. Transplant., 11: 211-214, 2013.

13- KUTINOVA A., WOODWARD R.S., RICCI J.F. and BRENNAN D.C.: The incidence and cost of sepsis and pneumonia before and after renal transplantation in the United States. Am. J. Transplant., 6: 129-139, 2006.

14- WATT K.D., PEDERSEN R.A., KREMERS W.K., HEIMBACH J.K. and CHARLTON M.R.: Evolution of causes and risk factors for mortality post-liver transplant: Results of the NIDDK long-term follow-up study. Am. J. Transplant., 10: 1420-1427, 2010.

15- LIU L., XUESONGPENG X., LIJUAN CHU L., et al.: Analysis of early-stage infection risk factors after living donor liver transplantation. Afr. J. Microbiol. Res., 4 (16): 1747-1753, 2010.

16- AL-HASAN M.N., RAZONABLE R.R., ECKELPASSOW J.E. and BADDOUR L.M.: Incidence rate and outcome of Gram-negative bloodstream infection in solid organ transplant recipients. Am. J. Transplant., 9: 835843,2009

17- ALLEN U. and GREEN M.: Prevention and treatment of infectious complications after solid organ transplantation in children. Pediatr. Clin. North. Am., 57: 459-479, 2010.

18- LINARES L., GARCÍA-GOEZ J.F., CERVERA C., ALMELA M., SANCLEMENTE G., COFÁN F., RICART M.J., NAVASA M. and MORENO A.: Earlybacteremia after solid organ transplantation. Transplant. Proc., 41: 2262-2264, 2009.

19- GAUTAM M., CHOPRA K.B., DOUGLAS D.D., STEWART R.A. and KUSNE S.: Streptococcus salivarius bacteremia and spontaneous bacterial peritonitis in liver transplantation candidates. Liver Transpl., 13: 1582-1588, 2007.

20- AMY S. COLLINS, B.S., B.S.N.: Preventing Health CareAssociated Infections.Chapter 41 in 'Patient Safety and Quality: An Evidence-Based Handbook for Nurses'. Editor: Ronda G. Hughes, AHRQ Publication No. 08-0043 April, Pag 1073, 2008. 
21- Health Protection Scotland: Targeted Literature Review: What are the Key Infection Prevention and Control Recommendations to Inform a Peripheral Vascular Catheter (PVC) Maintenance Care Quality Improvement Tool? tinvurl.com/HPS-PVC-Rev.. 2012.

22- Department of Health: High ImpactIntervention No 2: Peripheral Intravenous Cannula Care Bundle. tinyurl.com/ DH-HIA2-cannula, 2011.

23- REDDY P., ZEMBOWER T.R., ISON M.G., BAKER T.A. and STOSOR V.: Carbapenem-resistant Acinetobacter baumannii infections after organ transplantation. Transpl. Infect. Dis., 12:87-93, 2010.

24- ABBO A., NAVON-VENEZIA S., HAMMER-MUNTZ O., KRICHALI T., SIEGMAN-IGRA Y. and CARMELI Y.: Multidrug-resistant Acinetobacter baumannii. Emerg. Infect. Dis., 11: 22-29, 2005.

25- LI C., WEN T.F., MI K., WANG C., YAN L.N. and LI B.: Analysis of infections in the first 3-month after living donor liver transplantation. World J. Gastroenterol., 18 : 1975-1980, 2012

26- WEBSTER J., et al.: Clinically indicatedreplacement versus routine replacement ofperipheral venous catheters. Cochrane Database Systematic Review, 3: CD007798, 2010.

27- DOUGHERTY L. and LISTER S.: The Royal Marsden-
Manual of Clinical Nursing Procedures. Oxford: WileyBlackwell, 2008.

28- Royal College of Nursing: Standards for Infusion Therapy. London: RCN. tinyurl.com/RCN-Infusion, 2010.

29- SHIELDS R.K., CLANCY C.J., GILLIS L.M., et al.: Epidemiology, clinical char-acteristics and outcomes of extensively drug resistant Acinetobacter baumannii infections among solid organ transplant recipients. PLoS One., 7: e52349, 2012.

30- DE GOUVÊA E.F., MARTINS I.S., HALPERN M., et al.: The influence of car-bapenem resistance on mortality in solid organ transplant recipients with Acinetobacter baumannii infection. BMC Infect. Dis., 12: 351, 2012.

31- KIM Y.J., YOON J.H., KIM S.I., et al.: High mortality associated with Acinetobacter species infection in liver transplant patients. Transplant. Proc., 43: 2397-2399, 2011.

32- MORENO A., CERVERA C., GAVALDÁ J., et al.: Bloodstream infections among transplant recipients: Results of a nationwide surveillance in Spain. Am. J. Transplant., 7: 2579-2586, 2007.

33- WAN Q., XIAO X., YE Q. and ZHOU J.: Risk factors for bloodstream infections in liver or kidney transplantation recipients. Zhong Nan Da Xue Xue Bao Yi Xue Ban, 37 924-927. Chinese, 2012.

\section{العوامل المتنبأه بحدوث العدوى والوفيات فى زراعة الكبد اللمتبرئ الحبى الحيى}

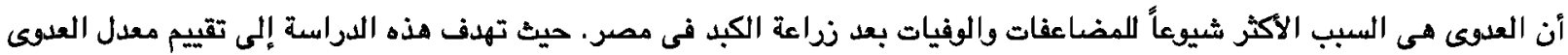

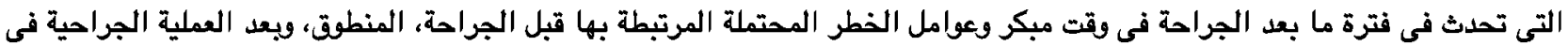

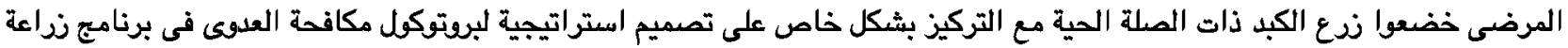

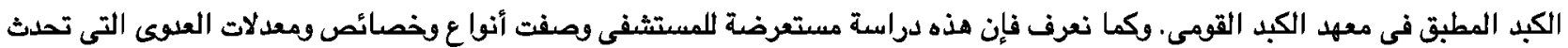

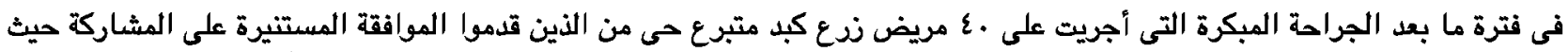

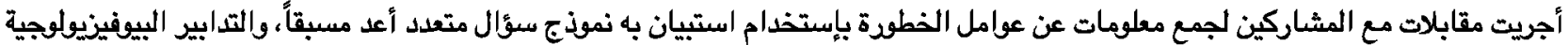
وقائمة المراجعة.

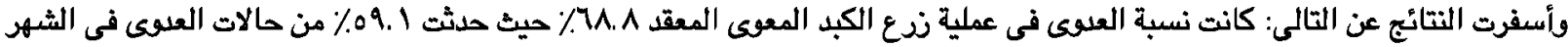

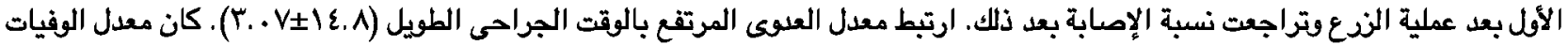

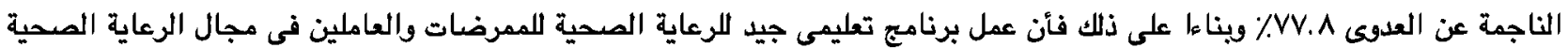

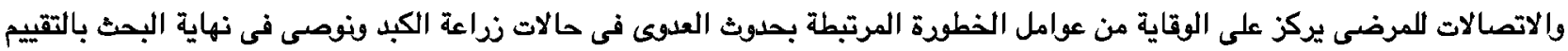

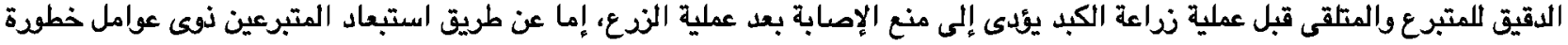
الإصابة بالعلوى بعد عملية الزدع أو عن طريق تحديد الحاجة إلى برنامجي علاجى قوى بالمضادات الميوية للميكروبات بعد عملية زراعة الكبد. 